\title{
The Impact of Patient Education with a Smartphone Application on the Quality of Bowel Preparation for Screening Colonoscopy
}

\author{
JeongHyeon Cho, SeungHee Lee, Jung A Shin, Jeong Ho Kim and Hong Sub Lee \\ Department of Gastroenterology, Seonam University College of Medicine, Myongji Hospital, Goyang, Korea
}

Background/Aims: Few studies have evaluated the use of a smartphone application (app) for educating people undergoing colonoscopy and optimizing bowel preparation. Therefore, this study was designed to develop a smartphone app for people to use as a preparation guide and to evaluate the efficacy of this app when used prior to colonoscopy.

Methods: In total, 142 patients (male:female $=84: 58$, mean age $=43.5 \pm 9.3$ years), who were scheduled to undergo a colonoscopy at Myongji Hospital, were enrolled in this study. Seventy-one patients were asked to use a smartphone app that we had recently developed to prepare for the colonoscopy, while the 71 patients of the sex and age-matched control group were educated via written and verbal instructions.

Results: The quality of bowel cleansing, evaluated using the Boston Bowel Preparation Scale, was significantly higher in the smartphone app group than in the control group ( $7.70 \pm 1.1$ vs. $7.24 \pm 0.8$, respectively, $p=0.007$ by $t$-test). No significant differences were found between the two groups regarding work-up time and the number of patients with polyps.

Conclusions: In this study, targeting young adults ( $\leq 50$ years), the bowel preparation achieved by patients using the smartphone app showed significantly better quality than that of the control group. Clin Endosc 2017;50:479-485

Key Words: Colonoscopy; Enema; Mobile applications; Colonic neoplasms

\section{INTRODUCTION}

Colorectal cancer is the third most commonly diagnosed cancer worldwide. ${ }^{1}$ Colonoscopy has been one of the most effective tools used for the detection of colorectal cancer. ${ }^{2} \mathrm{~A}$ successful colonoscopy is dependent on the quality of bowel preparation. ${ }^{3}$ Inadequate bowel preparation results in negative consequences for the examination, including missed lesions, ${ }^{4,5}$ procedural difficulties, and increase in overall colonoscopy cost. ${ }^{6}$ Despite the importance of bowel preparation, up to $25 \%$ of all bowel preparations are considered as inadequate. ${ }^{7}$ Inadequate bowel preparations are associated with old age, high

Received: January 21, 2017 Revised: March 14, 2017

Accepted: April 2, 2017

Correspondence: Hong Sub Lee

Department of Gastroenterology, Seonam University College of Medicine, Myongji Hospital, 55 Hwasu-ro 14 beon-gil, Deokyang-gu, Goyang 10475, Korea Tel: +82-31-810-5335, Fax: +82-31-969-0500, E-mail: epoch0123@mjh.or.kr

cc This is an Open Access article distributed under the terms of the Creative Commons Attribution Non-Commercial License (http://creativecommons.org/ licenses/by-nc/3.0) which permits unrestricted non-commercial use, distribution, and reproduction in any medium, provided the original work is properly cited. degree of physical inactivity, previous failure to adequately prepare for a colonoscopy, and lack of adherence to instructions. $^{8}$ Although many previous researchers have evaluated interventions such as recommending a low residue diet, coordinating the timing of administration, and combining bowel cleansing agents, there still exists controversy about effective ways to educate patients about bowel cleansing.

It was announced that Koreas smartphone penetration rate has reached 83 percent, putting the nation in fourth place when global smartphone use was ranked..$^{10}$ Moreover, in the future, the penetration of the smartphone is expected to experience a massive increase. Various educational applications (apps) are being prepared involving a number of health-related apps. There are many apps for patients suffering from diseases such as cardiovascular disease ${ }^{11}$ and diabetes, ${ }^{12,13}$ apps which are effective in some ways for patient education.

However, despite the use of the smartphone as a common gadget, little information exists regarding the effect of the smartphone app in bowel preparation. To the best of our knowledge, there is no smartphone app for colonoscopy-re- 
lated bowel cleansing in Korea. Therefore, the purpose of our trial is to develop a smartphone app for patients to use as a preparation guide for this procedure, and to validate the efficacy of bowel preparation when a smartphone app is used.

\section{MATERIALS AND METHODS}

\section{Study design}

This study consisted of two phases: an app development phase and a validation study.

\section{Educational app development}

To determine the contents of the smartphone app, the authors decided they should carry out an extensive review of other health-related educational apps and existing educational brochures and leaflets for colonoscopy. After determining the app contents, the design phase was implemented to specify learning objectives, contents, and the methods of educating patients about bowel preparation. Based on the analysis, an educational app was designed by Dr. Lee and Dr. Cho. Finally, Dr. Cho, one of the authors of this article who also works in the gastroenterology department at Myongji Hospital, devel- oped the app.

The learning objectives comprised of the following 4 main sections: (1) Colonoscopy, (2) An example of poor bowel preparation, (3) Dietary recommendations, and (4) How to make and drink the bowel-cleansing agent. These objectives are shown in Fig. 1. This app was designed with the intention of informing patients about factors that are key to a successful colonoscopy (e.g., how to consume a liquid diet and perform bowel cleansing), according to the directions of the physicians.

Unlike other apps used for colonoscopy bowel cleansing, the alarm time of this app is set at 3 days before the colonoscopy. To be concrete, each time $(07: 00,12: 00,18: 00)$ a patient eats a meal, the app lets them know the type of diet that is necessary to improve bowel cleansing. By simply entering the date of the colonoscopy in the app, the alarm function starts. In addition, it was thought that providing various examples of poor bowel preparation using visual animations and pictures could motivate the patients to effectively clean their bowels.

\section{Main study}

The second stage of this study was a prospective, endoscopist-blinded, matched, controlled study involving patients scheduled to receive colonoscopy at the gastroenterology de-

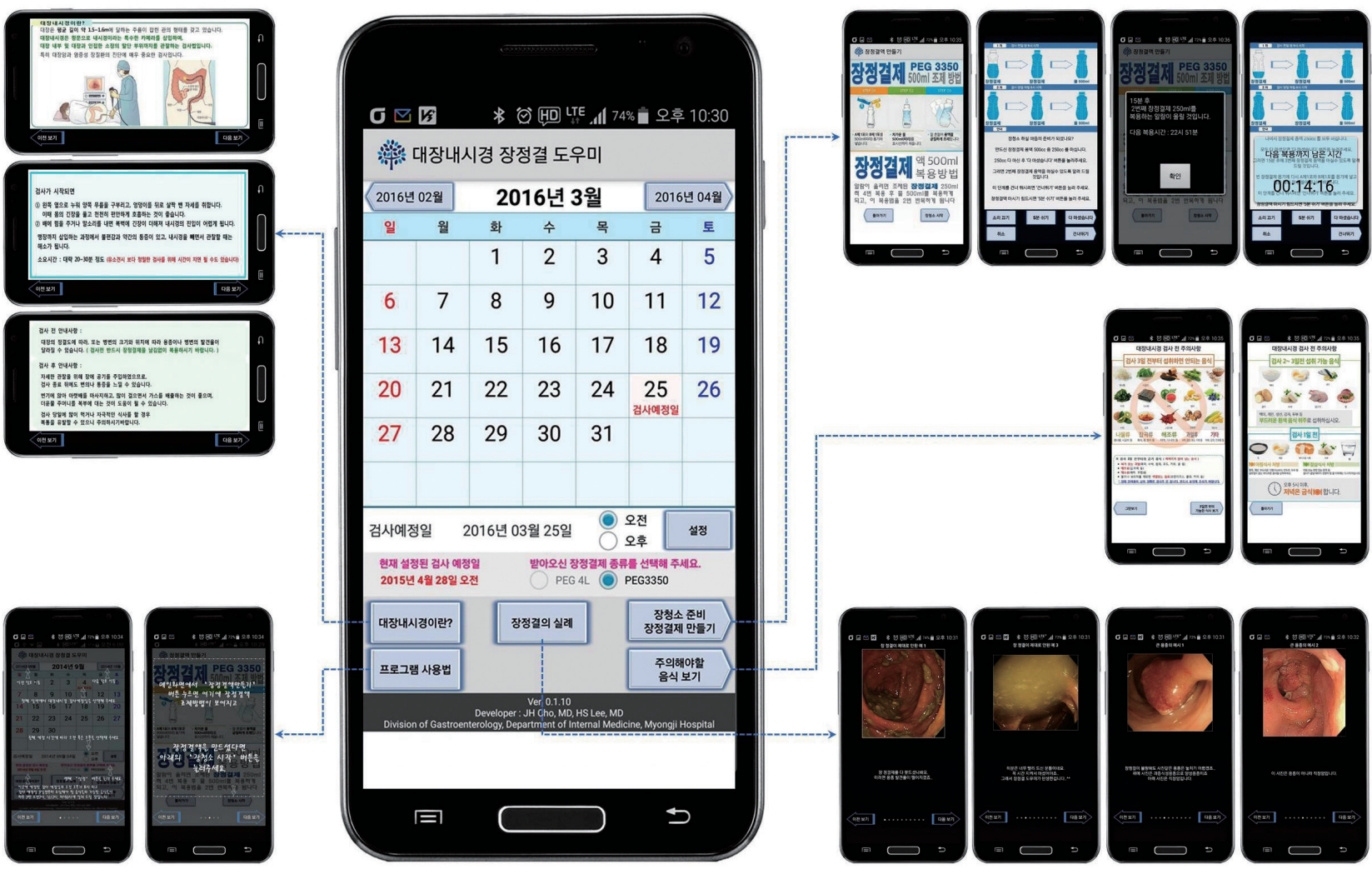

Fig. 1. A main screen calendar view of a smartphone with 5 sections consisting of the procedure explanation, usage method for the application, an example of areal case, explanations regarding the use of the oral bowel cleansing solution, and foods to avoid. 


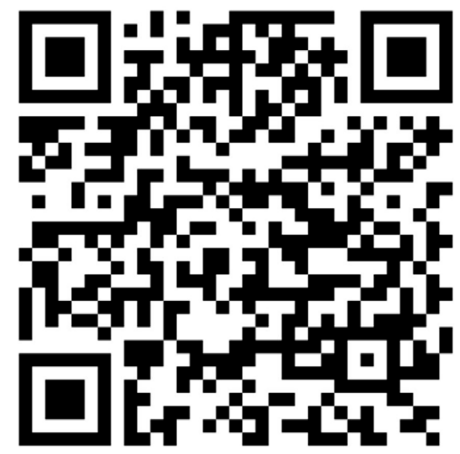

Fig. 2. Quick response code of the bowel preparation application.

partment of Myongji Hospital in Korea. The study protocols were approved by the Institutional Review Board of Myongji Hospital, according to the ethical guidelines of the Declaration of Helsinki (MJH14-015). This trial was registered with the Clinical Research Information Service (CRIS) at https://cris. nih.go.kr (KCT0001479).

The patients were asked to use a new smartphone app that educates the user on colonoscopy preparation, while the age and sex-matched (at 2-year age intervals) control group was educated using the existing verbal and written instructions. The patients in the smartphone group were educated about how to download the app onto their smartphones. The smartphone app assisted bowel cleansing by explaining the colonoscopy procedure, showing pictures of various examples of preparation quality, and explaining how to make the purgative solution. This app, which was designed for the Android operating system (OS), can be freely downloaded (Fig. 2).

All the patients were given the same bowel cleansing product-2 L of a solution containing polyethylene glycol (PEG) plus ascorbate (Coolprep ${ }^{\circledR}$; Taejoon Pharm., Seoul, Korea). Three days before the colonoscopy, they were instructed to refrain from eating high-fiber foods, as well as foods containing seeds, sea algae, etc. On the day before exam, they were asked to eat a light dinner, followed by fasting, with the exception of drinking water. On the day of the procedure, they were requested to drink the cleansing product between 8 and 4 hours before the exam. All colonoscopies were performed in the afternoon. All the colonoscopies were performed by two board-certified, experienced endoscopists (Dr. Hong Sub Lee and Dr. Jeong Ho Kim), each of whom have performed more than 5,000 colonoscopies.

\section{Subjects}

Patients who were scheduled to receive a colonoscopy at Myongji Hospital were eligible for participation in the study. The inclusion criteria were as follows: (1) young adults $(\leq 50$ years old) who possessed an Android smartphone that they could skillfully use and (2) patients who signed the informed consent. The exclusion criteria were as follows: (1) patients with severe comorbidities (cardiovascular disease, chronic renal disease, etc.) who could not tolerate an endoscopic procedure; (2) patients with mental illness; (3) patients with an allergy to the PEG solution; (4) patients with a history of colorectal surgery; (5) patients with planned endoscopic therapy; and (6) patients who did not sign the informed consent.

Well-trained nurses employed at the gastroenterology endoscopy center provided the patients with education about bowel preparation. All the patients provided written informed consent before they participated in the study.

\section{Determination of the sample size}

In a previous study that provided patient education using animation, ${ }^{14}$ the average the Boston Bowel Preparation Scale (BBPS) scores of the control group (those who received standard education materials) and the study group (those who received animation-based education) were 6.1 (standard deviation $[S D]=2.2)$ and $7.4(S D=1.9)$, respectively. The number of patients in each group of present study was calculated to determine the results that would reflect a significance level ( $\alpha$ ) of 0.05 and a power of 0.90 . Therefore, we calculated that 124 patients, including 62 patients in the intervention group and 62 patients in the control group, were needed. We chose to enroll more than 140 patients to allow for an approximate drop of $10 \%$.

\section{Outcome measures}

The primary endpoint of this study was the quality of bowel cleansing. The quality of bowel preparation was evaluated using the BBPS. ${ }^{15}$ Using this scale, the quality of bowel preparation was given a score of 0 to 3 for each of the three colonic segments (that is, left, transverse, and right). Finally, the total score was calculated, which ranged from 0 to 9 (higher scores mean better bowel preparation). The BBPS score was validated in Korea. ${ }^{16}$ In such studies, it was reported that the polyp detection rate is higher in people with higher BBPS scores than in those with lower BBPS scores.

The secondary outcomes included cecal intubation time, withdrawal time, and the number of patients with polyps. The third outcome was the degree of satisfaction with the smartphone app for bowel preparation. The patients' satisfaction was assessed with a questionnaire, which included the question, "Are you satisfied with the education delivery method for the preparation of a colonoscopy?". The answer to the question was evaluated based on the10-point Likert scale (a 0 to 10 scale in which $0=$ "extremely dissatisfied" and $10=$ "extremely satisfied"), a scale commonly used to assess responses to survey questionnaires. ${ }^{17}$ The 10 -point scale in this study can detect subtle changes than a 7-point or 5-point scale. In addi- 
tion, The Likert scale using the response points and markers is easier to understand, compared with the typical comprehension of a visual analogue scale.

\section{Statistical analyses}

Primary and secondary outcomes were assessed using Student's $t$-test. Questionnaire responses were evaluated with the chi-square test. Analyses were performed with SPSS software V.14.0 (SPSS Inc., Chicago, IL, USA) for Windows. A p-value of less than 0.05 was considered statistically significant. To minimize selection bias from lack of randomization, subgroup analysis by one-to-one propensity matching was performed using R Statistical Software 3.3.3 (The R Foundation for Statistical Computing, Vienna, Austria). The covariates for matching estimation were age, gender, body mass index (BMI), previous abdominal surgery, history of hypertension, diabetes, and hypothyroidism.

\section{RESULTS}

\section{Patients' characteristics}

From July 2014 through September 2015, 899 potential study participants were considered for this study. Among them, 757 patients were excluded for the following reasons: they failed to meet the inclusion criteria, they did not keep their procedure appointment, or they withdrew their consent for the procedure. Finally, 142 patients with a scheduled elective colonoscopy were enrolled. Seventy-one patients used a smartphone app that we recently developed, and the 71 patients of the sex and age-matched control group was educated using the existing verbal and written instructions.

Table 1. Demographic Data of 142 Participants

\begin{tabular}{|c|c|c|c|}
\hline Clinical feature & $\begin{array}{l}\text { Smart group } \\
\quad(n=71)\end{array}$ & $\begin{array}{c}\text { Control group } \\
(n=71)\end{array}$ & $p$-value \\
\hline Age & $42.3 \pm 10.3$ & $44.8 \pm 5.4$ & 0.107 \\
\hline Sex (Male/Female) & $42 / 29$ & $42 / 29$ & \\
\hline Hypertension & 3 & 9 & $0.028^{\mathrm{a})}$ \\
\hline Diabetes & 4 & 1 & 0.260 \\
\hline Hypothyroidism & 1 & 3 & 0.220 \\
\hline BMI & $23.8 \pm 3.8$ & $24.3 \pm 3.8$ & 0.447 \\
\hline $\begin{array}{l}\text { Operation } \\
\text { (abdomen) }\end{array}$ & 12 & 5 & 0.146 \\
\hline $\begin{array}{l}\text { Previous } \\
\quad \text { colonoscopy }\end{array}$ & 34 & 19 & $0.009^{\mathrm{a})}$ \\
\hline
\end{tabular}

Values are presented as mean \pm standard deviation or numbers. BMI, body mass index.

${ }^{\text {a) }}$ Statistically significant.
Concerning the basic characteristics of the two groups (Table 1), mean age (app group: $42.3 \pm 10.3$ years vs. control group: $44.8 \pm 5.4$ years, $p=0.107$ ) and BMI (app group: $23.8 \pm 3.8 \mathrm{~kg} / \mathrm{m}^{2}$ vs. control group: $24.3 \pm 3.8 \mathrm{~kg} / \mathrm{m}^{2}, p=0.447$ ) were similar, but the number of patients with a history of a previous colonoscopy were significantly higher in the app group.

\section{Outcomes of bowel cleansing}

The mean BBPS scores in the smartphone app group were significantly higher compared to those of the control group (app group: $7.70 \pm 1.1$ vs. control group: $7.24 \pm 0.8, p=0.007$ ) (Table 2). Although the scores of the BBPS for the transverse colon were similar in both the groups, the scores for the left and right colons were significantly higher in the app group compared to those of control group.

Subgroup analysis of those without a history of previous colonoscopy was done, because previous experience of colonoscopy can be a serious bias. After one-to-one propensity matching for subgroup analysis, there were 37 patients in each group. Based on the previously discussed subgroup analysis, the mean BBPS scores in the app group were significantly higher compared to those of the control group (app group: $7.73 \pm 1.3$ vs. control group: $7.16 \pm 0.8, p=0.031$ ) (Table 3 ). However, the baseline characteristics including age, sex, history of abdominal operations, and BMI were significantly different between the two groups.

\section{Procedure time and the polyp detection rate}

There was no significant difference between the two groups with respect to the number of patients with polyps (app group: $23 / 71$ vs. control group: $15 / 71, p=0.129$ ) and there were no significant differences in the detection of a tubular adenoma between the two groups. In addition, there were no significant differences in the duration of work-up time (app group: 16.36 \pm 7.5 minutes vs. control group: $15.54 \pm 6.6$ minutes, $p=0.493$ ), including the cecal intubation time, between the two groups.

Table 2. Bowel Cleansing Scores Assessed by Boston Bowel Preparation Scale

\begin{tabular}{cccc}
\hline & $\begin{array}{c}\text { Smart group } \\
(\boldsymbol{n}=\mathbf{7 1})\end{array}$ & $\begin{array}{c}\text { Control group } \\
(\boldsymbol{n}=\mathbf{7 1})\end{array}$ & $\boldsymbol{p}$-value \\
\hline BBPS, whole colon & $7.70 \pm 1.1$ & $7.24 \pm 0.8$ & $0.007^{\mathrm{a})}$ \\
$\quad$ Right colon & $2.42 \pm 0.5$ & $2.18 \pm 0.4$ & $0.007^{\mathrm{a})}$ \\
\hline Transverse colon & $2.61 \pm 0.5$ & $2.61 \pm 0.4$ & 1.000 \\
Left colon & $2.68 \pm 0.5$ & $2.45 \pm 0.5$ & $0.012^{\mathrm{a})}$ \\
\hline
\end{tabular}

Values are presented as mean \pm standard deviation. BBPS, Boston bowel preparation scale.

a) Statistically significant. 
Table 3. Subgroup Analysis Propensity Score Matching Using R Studio in Participants without Previous Colonoscopy

\begin{tabular}{lccc}
\hline & $\begin{array}{c}\text { Smart group } \\
(\boldsymbol{n}=37)\end{array}$ & $\begin{array}{c}\text { Control group } \\
(\boldsymbol{n}=37)\end{array}$ & $\boldsymbol{p}$-value \\
\hline Age & $38.81 \pm 9.7$ & $45.30 \pm 7.2$ & $0.002^{\mathrm{a})}$ \\
Sex (Male/Female) & $17 / 20$ & $30 / 7$ & $0.002^{\mathrm{a})}$ \\
\hline Hypertension & 1 & 5 & 0.088 \\
Diabetes & 1 & 1 & 1.000 \\
\hline Hypothyroidism & 0 & 2 & 0.152 \\
Operation & 7 & 1 & $0.025^{\mathrm{a})}$ \\
$\quad$ (abdomen) & & & \\
BMI & $22.81 \pm 3.6$ & $25.4 \pm 3.8$ & $0.003^{\mathrm{a})}$ \\
BBPS, whole colon & $7.73 \pm 1.3$ & $7.16 \pm 0.8$ & $0.031^{\mathrm{a})}$ \\
\hline \multicolumn{1}{c}{ Right colon } & $2.35 \pm 0.6$ & $2.19 \pm 0.3$ & 0.192 \\
\hline Transverse colon & $2.65 \pm 0.5$ & $2.62 \pm 0.4$ & 0.831 \\
\hline \multicolumn{1}{c}{ Left colon } & $2.73 \pm 0.6$ & $2.35 \pm 0.4$ & $0.004^{\mathrm{a})}$ \\
\hline
\end{tabular}

Values are presented as mean \pm standard deviation or numbers. BMI, body mass index; BBPS, Boston bowel preparation scale.

${ }^{\text {a) }}$ Statistically significant.

\section{Satisfaction}

The patients' satisfaction with the bowel preparation administered in both the groups was evaluated through a questionnaire. The mean score of the questionnaire was significantly higher in the app group than that of the control group (app group: $7.62 \pm 2.2$ vs. control group: $5.97 \pm 2.2, p<0.001$ ).

\section{DISCUSSION}

The purpose of this study was to develop a smartphone app for bowel cleansing and to validate the efficacy of the app. This is the first study to report the development and use of a smartphone app for bowel cleansing in the Korean language. In the present study, BBPS scores were significantly higher in the app group compared to those of the control group (app group: $7.70 \pm 1.1$ vs. control group: $7.24 \pm 0.8, p=0.007$ ), and the patients' satisfaction scores was higher in the app group compared to those of the control group. A smartphone app can assist with bowel preparation by displaying text instructions, visual aids, and alerting the patients of time. Through the smartphone app, the patients can learn when the diet restrictions should start and they can be repeatedly reminded of the foods they should avoid. These could be possible explanations of how bowel preparation improved using the smartphone app.

Results of this study correspond well with those of an earlier study which reported that the use of a smartphone app, as a means of education, was associated with improved quality of bowel preparation. ${ }^{18}$ That study reported improved bowel preparation and patient satisfaction with the use of a smartphone app, compared with that of the control group.

Some studies, which employed an education intervention using simple visual aids ${ }^{18}$ or additional explanations, ${ }^{19}$ had no influence on the quality of bowel preparation in patients prior to colonoscopy. ${ }^{20}$ However, other studies using visual aids such as a booklet ${ }^{21,22}$ and an educational video, ${ }^{23,24}$ demonstrated that patient education can have a positive effect on bowel preparation. The possible reason for the mixed findings among many studies about education regarding bowel cleansing is just to stimulate temporary anxiety about poor bowel preparation to motivate bowel preparation compliance. On the other hand, the results of some studies demonstrated improvements in bowel preparation with the use of the telephone ${ }^{25}$ and mobile phone messages ${ }^{26}$ to reinforce diet instructions and timetables for ingestion of bowel preparation agents.

These studies suggest that education by more interactive and intensive methods may be needed to improve bowel cleansing. Therefore, the app presented in this study of bowel preparation is a method involving education by visual aids combined with a reminder function. This current study proves that a smartphone app can significantly improve bowel preparation for colonoscopy. This smartphone app is freely available on the Android OS market and anyone can download it. As of December 24, 2016, the download number had reached over 1,000 .

In this study, the number of detected polyp was higher in those who used the smartphone app than those receiving written explanations, but not significantly different (app group: 23 vs. control group: $15, p=0.129$ ). A higher polyp detection rate has been found in patients with adequate bowel preparation. ${ }^{8}$ The reason to fail to show significant difference in current study may be attributable to a relatively small sample size. Studies employing other educational methods failed to show a significant difference in polyp detection rate. ${ }^{9}$ Therefore, a large number of patients would be needed to discriminate the difference in the rate of polyp detection.

There are several limitations to this study.

First, a randomized controlled trial could not be done. The collection of patients was not easy because this app had not been validated. In addition, some people who were scheduled to receive a colonoscopy were afraid of using the smartphone app in place of written explanations. Since most people thought that a colonoscopy is a once-in-a-lifetime checkup usually performed for health screening and not for the evaluation of chronic disease, they were reluctant to learn how to use our app. Thus, there is a possibility of a selection bias. Also considering that the study involved patients with a history of previous colonoscopy, this could also 
affect the efficacy of bowel preparation. To reduce selection bias due to the lack of randomization, subgroup analysis using one-to-one propensity matching was done. Despite small differences in the bowel preparation scale scores, results of the subgroup analysis for patients without a previous colonoscopy suggest that bowel preparation by smartphone app is superior to written instruction. Additionally, further evaluation using a randomized controlled trial could be done safely without the risk of poor bowel preparation. Further studies using a more revised smartphone app that gathers feedback from its users could have better results than those of the current study.

Second, only smartphone users with an Android OS could participate in this study and other smartphone users could not participate in this study. An individual's choice of smartphone varies based on different factors and may influence bowel-cleansing. ${ }^{27}$ Therefore, the results of this study may not be applicable to the general population. However, according to a report of the International Data Corporation, which conducts American market research, the Android OS market share accounts for up to $86.8 \%$ of the global smartphone OS market share. ${ }^{28}$ Furthermore, according to the report from the Korea Internet \& Security Agency, the Android OS accounted for as much as $85.82 \%$ of the smartphone OS market share in Korea. ${ }^{29}$ Although Android accounts for the majority of the smartphone market, there is a need to design an app with an iPhone-based OS in the future.

Third, this study was a single-center study and the number of people who participated in this study was small. Multi-center studies should be done to confirm the efficacy of a smartphone app for bowel preparation.

Fourth, an inclusion criterion of this study was that patients had to be less than 50 years old. Usually, a colonoscopy is recommended for patients aged 50 years and above and in this older age group, people are not as familiar with smartphone apps. Since the polyp detection rate in young people is increasing, tools for diverse education are becoming necessary.

In conclusion, this study reveals that bowel preparation, as assessed by the BBPS, performed with a smartphone app was significantly better than the quality of bowel preparation done by following written paper instructions. In addition, patient satisfaction with bowel preparation was significantly better in the group of patients using the smartphone app.

\section{Conflict of Interest}

The authors have no financial conflicts of interest.

\section{Author contributions}

Conceptualization: Hong Sub Lee

Data curation: JeongHyeon Cho
Formal analysis: HSL

Funding acquisition: HSL

Investigation: SeungHee Lee, Jung A Shin

Methodology: HSL

Project administration: HSL

Resources: HSL

Software: JHC

Supervision: Jeong Ho Kim

Validation: HSL

Visualization: JHC

Writing-original draft: JHC, SHL

Writing-review\&editing: HSL

\section{REFERENCES}

1. Ferlay J, Soerjomataram I, Ervik M, et al. GLOBOCAN 2012 v1.0, cancer incidence and mortality worldwide: IARC CancerBase No. 11 [Internet]. Lyon: International Agency for Research on Cancer; c2013 [cited 2016 Dec 17]. Available from: http://publications.iarc.fr/Databases/ Iarc-Cancerbases/Globocan-2012-Estimated-Cancer-Incidence-Mortality-And-Prevalence-Worldwide-In-2012-V1-0-2012.

2. U.S. Preventive Services Task Force. Screening for colorectal cancer: U.S. preventive services task force recommendation statement. Ann Intern Med 2008;149:627-637.

3. Clark BT, Rustagi T, Laine L. What level of bowel prep quality requires early repeat colonoscopy: systematic review and meta-analysis of the impact of preparation quality on adenoma detection rate. Am J Gastroenterol 2014;109:1714-1723; quiz 1724

4. van Rijn JC, Reitsma JB, Stoker J, Bossuyt PM, van Deventer SJ, Dekker E. Polyp miss rate determined by tandem colonoscopy: a systematic review. Am J Gastroenterol 2006;101:343-350.

5. Chokshi RV, Hovis CE, Hollander T, Early DS, Wang JS. Prevalence of missed adenomas in patients with inadequate bowel preparation on screening colonoscopy. Gastrointest Endosc 2012;75:1197-1203.

6. Rex DK, Imperiale TF, Latinovich DR, Bratcher LL. Impact of bowel preparation on efficiency and cost of colonoscopy. Am J Gastroenterol 2002;97:1696-1700.

7. Harewood GC, Sharma VK, de Garmo P. Impact of colonoscopy preparation quality on detection of suspected colonic neoplasia. Gastrointest Endosc 2003;58:76-79.

8. Froehlich F, Wietlisbach V, Gonvers JJ, Burnand B, Vader JP. Impact of colonic cleansing on quality and diagnostic yield of colonoscopy: the European panel of appropriateness of gastrointestinal endoscopy European multicenter study. Gastrointest Endosc 2005;61:378-384.

9. Chang CW, Shih SC, Wang HY, et al. Meta-analysis: the effect of patient education on bowel preparation for colonoscopy. Endosc Int Open 2015;3:E646-E652.

10. Cho JY. Korea ranks 4 th in smartphone penetration rate [Internet]. Seoul: BusinessKorea; c2015 [updated 2015 Jul 8; cited 2016 Dec 23]. Available from: http://www.businesskorea.co.kr/english/news/ict/11329hand-held-computers-korea-ranks-4th-smartphone-penetration-rate.

11. Cho MJ, Sim JL, Hwang SY. Development of smartphone educational application for patients with coronary artery disease. Healthc Inform Res 2014;20:117-124.

12. Goh G, Tan NC, Malhotra R, et al. Short-term trajectories of use of a caloric-monitoring mobile phone app among patients with type 2 diabetes mellitus in a primary care setting. J Med Internet Res 2015;17:e33.

13. Conway N, Campbell I, Forbes P, Cunningham S, Wake D. mHealth applications for diabetes: user preference and implications for app development. Health Informatics J 2016;22:1111-1120.

14. Tae JW, Lee JC, Hong SJ, et al. Impact of patient education with cartoon visual aids on the quality of bowel preparation for colonoscopy. Gastrointest Endosc 2012;76:804-811. 
15. Lai EJ, Calderwood AH, Doros G, Fix OK, Jacobson BC. The Boston bowel preparation scale: a valid and reliable instrument for colonoscopy-oriented research. Gastrointest Endosc 2009;69(3 Pt 2):620-625.

16. Kim EJ, Park YI, Kim YS, et al. A Korean experience of the use of Boston bowel preparation scale: a valid and reliable instrument for colonoscopy-oriented research. Saudi J Gastroenterol 2014;20:219-224.

17. Harland NJ, Dawkin MJ, Martin D. Relative utility of a visual analogue scale vs. a six-point Likert scale in the measurement of global subject outcome in patients with low back pain receiving physiotherapy. Physiotherapy 2015;101:50-54.

18. Lorenzo-Zúñiga V, Moreno de Vega V, Marín I, Barberá M, Boix J. Improving the quality of colonoscopy bowel preparation using a smart phone application: a randomized trial. Dig Endosc 2015;27:590-595.

19. Calderwood AH, Lai EJ, Fix OK, Jacobson BC. An endoscopist-blinded, randomized, controlled trial of a simple visual aid to improve bowel preparation for screening colonoscopy. Gastrointest Endosc 2011;73:307314.

20. Modi C, Depasquale JR, Digiacomo WS, et al. Impact of patient education on quality of bowel preparation in outpatient colonoscopies. Qual Prim Care 2009;17:397-404.

21. Spiegel BM, Talley J, Shekelle P, et al. Development and validation of a novel patient educational booklet to enhance colonoscopy preparation. Am J Gastroenterol 2011;106:875-883.

22. Ergen WF, Pasricha T, Hubbard FJ, et al. Providing hospitalized patients with an educational booklet increases the quality of colonoscopy bowel preparation. Clin Gastroenterol Hepatol 2016;14:858-864.
23. Prakash SR, Verma S, McGowan J, et al. Improving the quality of colonoscopy bowel preparation using an educational video. Can J Gastroenterol 2013;27:696-700.

24. Park JS, Kim MS, Kim H, et al. A randomized controlled trial of an educational video to improve quality of bowel preparation for colonoscopy. BMC Gastroenterol 2016;16:64.

25. Liu X, Luo H, Zhang L, et al. Telephone-based re-education on the day before colonoscopy improves the quality of bowel preparation and the polyp detection rate: a prospective, colonoscopist-blinded, randomised, controlled study. Gut 2014;63:125-130.

26. Park J, Kim TO, Lee NY, et al. The effectiveness of short message service to assure the preparation-to-colonoscopy interval before bowel preparation for colonoscopy. Gastroenterol Res Pract 2015;2015:628049.

27. Lebwohl B, Wang TC, Neugut AI. Socioeconomic and other predictors of colonoscopy preparation quality. Dig Dis Sci 2010;55:2014-2020.

28. Baker S, Chau M, Jeronimo F, et al. Smartphone OS market share, 2016 Q3 [Internet]. Framingham (MA): IDC Research; c2016 [cited 2016 Dec 23]. Available from: https://www.idc.com/promo/smartphone-market-share/os;jsessionid=3F72C48231EE23D3C7AB44A0F25900B5.

29. Yoo JY. Internet jinheung-won, gugnae internet iyong hwangyeong hyeonhwang josa gyeolgwa balpyo [2014 domestic Internet environment survey] [Internet]. Seoul: Korea Internet \& Security Agency (KISA); c2015 [updated 2015 Feb 12; cited 2016 Dec 23]. Available from: https:// www.kisa.or.kr/notice/press_View.jsp? $m o d e=v i e w \& p \_N o=8 \& b$ $\mathrm{No}=8 \& d \_\mathrm{No}=1347$. 